\title{
Las dimensiones narrativas del comentario radiofónico en el magacín deportivo
}

MHCJ no5 | Año 2014

Hilario José Romero Bejarano | hromero83@hotmail.es

Artículo no5 (55)

Páginas 113 a 140

mhci.es

\section{Palabras clave}

Comentario; deporte; radio; magacín; narrativa.

Sumario

1. Introducción.

2. Metodología.

3. Rasgos generales del magacín deportivo.

4. Conceptualización y clasificación de los géneros radiofónicos.

5. Aspectos narrativos y discursivos del comentario.

6. Resultados y discusión.

7. Conclusiones.

8. Bibliografía.

9. Notas.

\section{Resumen}

El comentario se ha consolidado como uno de los géneros de mayor relevancia en el actual panorama radiofónico. La visión personal que imprime su autor y la capacidad que posee para albergar un amplio número de elementos y figuras expresivas lo convierten en uno de los principales referentes desde el punto de vista formal y de contenido. El magacín deportivo combina el éxito asociado a su formato de programa con la trascendencia que adquiere el deporte en la sociedad. Esta convergencia pone de manifiesto la doble dimensión informativa-espectacular de la radio deportiva, al tiempo que adquieren especial protagonismo su ubicación en la franja de la medianoche y el amplio número de géneros y registros radiofónicos diferentes que contiene. El objetivo de esta investigación es analizar los aspectos narrativos que definen al comentario deportivo en radio. Para ello se ha elaborado una muestra de 105 programas pertenecientes a las emisoras Cadena SER, COPE, Onda Cero y Abc Punto Radio. Se trata de valorar qué rol adquiere este género radiofónico en la programación deportiva, y de comparar su identidad como modelo de representación con respecto a los comentarios emitidos en los programas informativos de actualidad y que ya han sido estudiados previamente dentro de la comunidad científica. Los resultados obtenidos permitirán determinar el nivel de homogeneidad existente y las nuevas tendencias estéticas de la radio española.

\section{Forma de citar este artículo en las bibliografías}

Hilario José Romero Bejarano (2014): “Las dimensiones narrativas del comentario radiofónico en el magacín deportivo", en Miguel Hernández Communication Journal, n5, páginas 113 a 140. Universidad Miguel Hernández, UMH (Elche-Alicante). Recuperado el _ de de 20

de: http:/ / mhcj.es./index.php?journal=mhcj\&page $=$ article\&op $=$ view\&path $\square=59$ 


\title{
Narrative dimensions of the radio comment on the sports magazine
}

\author{
MHCJ no5 | Año 2014 \\ Artículo nำ5 (55) \\ Páginas 113 a 140 \\ mhcj.es
}

Hilario José Romero Bejarano | hromero83@hotmail.es

Keywords

Comment; sport; radio; magazine; narrative.

Summary

1. Introduction.

2. Methodology.

3. Main features of the sports magazine.

4. Conceptualization and classification of radio genres.

5. Narrative and discursive aspects of the comment.

6. Results and discussion.

7. Conclusions.

8. Bibliography.

9. Notes.

\begin{abstract}
The comment has become one of the most important genres in the current radio scene. Personal view and print the author has the ability to accommodate a large number of elements and expressive figures make it one of the main references from the formal point of view and content. Meanwhile, the sports magazine combines the success associated with its program format acquires the significance of sport in society. This convergence highlights the informative-show double dimension of sports radio, while acquiring special importance of its location in the Gaza midnight and the large number of different radio genres and records it contains. The objective of this research is to analyze the narrative aspects that define the sports commentary on radio. This was a sample of 105 programs belonging to the radio stations Cadena SER, COPE, Onda Cero and Abc Punto Radio. It takes assess what role this radio genre in sports programming, and compare their identity as model representations regarding the comments made in informative current affairs programs that have already been previously studied within the scientific community. The results will determine the existing level of homogeneity and the new aesthetic trends Spanish radio.
\end{abstract}

\section{How to cite this paper in bibliographies}

Hilario José Romero Bejarano (2014): “Las dimensiones narrativas del comentario radiofónico en el magacín deportivo”, en Miguel Hernández Communication Journal, n5, páginas 113 a 140. Universidad Miguel Hernández, $\mathrm{UMH}$ (Elche-Alicante). Recuperado el__ de ___ de 20

de: http: / / mhcj.es. $/$ index.php?journal=mhcj\&page $=$ article\&op $=$ view\&path $[=59$ 


\section{Introducción}

El comentario es uno de los géneros radiofónicos de mayor interés académico y profesional debido a su naturaleza argumentativa y a la libertad expresiva y estilística con la que se asocia. De hecho, refleja fielmente el progresivo incremento de contenidos de opinión que se ha producido durante las últimas décadas, al tiempo que se ha consolidado en todo un referente narrativo y discursivo a la hora de estudiar el uso de los recursos del lenguaje radiofónico por parte de las diferentes emisoras.

El proceso de sistematización que más se ajusta a los objetivos planteados en la presente investigación se relaciona con el modelo de análisis de los géneros radiofónicos planteados por Martínez-Costa y Herrera Damas. Su propuesta incorpora cuatro variables descriptivas: contenido, recursos estilísticos, condiciones de producción y realización, e integración en la programación (2004: 141). A partir de dicho modelo estos autores han realizado diferentes estudios entre los cuales se encuentra el análisis de los rasgos que definen la identidad narrativa del comentario radiofónico.

El deporte se ha configurado tradicionalmente como una apuesta segura de éxito de audiencia para las emisoras de radio. Junto a ello, los programas deportivos han conseguido aglutinar los principales aspectos narrativos, discursivos y estilísticos que han determinado la evolución de la radio española. En la actualidad, el carácter dialógico y polifónico de los espacios deportivos, el estilo distendido con el que se llevan a cabo o el mayor predominio de contenidos de opinión, son sólo algunos de los rasgos que comparte un amplio número de programas de diversa temática. No obstante, la comunicación deportiva en este medio cuenta con un reducido número de estudios dentro de la comunidad científica.

El objetivo de la investigación es analizar la identidad narrativa del comentario deportivo en radio. La trascendencia que ha adquirido este género en los últimos veinte años se refleja en su presencia tanto en programas de deportes como en otros de temática más general. En estos últimos casos las voces encargadas de llevarlos a cabo suelen coincidir con la figura del presentador o de algún contertulio del magacín deportivo de la emisora en cuestión. Sirvan como ejemplos los comentarios que realizan durante el año 2013 José Ramón de la Morena en el magacín Hoy por Hoy (Cadena SER) y Manolo Lama en el programa La Mañana (COPE).

De forma más específica, los objetivos planteados en el presente estudio son los siguientes:

- Conocer la presencia y el protagonismo del comentario en el magacín deportivo.

- Estudiar la autoría, el tamaño y la ubicación más habitual del mismo.

- Analizar las dimensiones espacio-temporales sobre las que se lleva a cabo. 
- Conocer el rol que adquieren los cuatro elementos del lenguaje radiofónico en su desarrollo: la palabra, la música, los efectos sonoros y el silencio.

- Estudiar el estilo enunciativo más utilizado en la emisión de este género.

- Valorar el número y el tipo de apelaciones directas o indirectas a los oyentes.

- Analizar los enfoques temáticos más relevantes en este género.

- Comparar los objetivos anteriores en función de la emisora seleccionada.

A partir de estos objetivos se han configurado ocho hipótesis específicas:

- H1: el comentario es uno de los géneros radiofónicos que aparece con más continuidad en el magacín deportivo.

- H2: es realizado y leído en antena por una sola voz, su tamaño tiende a ser mediogrande y se ubica en los instantes finales de la emisión.

- H3: el comentario es emitido en directo, no incorpora cortes de voz y su realización espacial se basa en el primer plano y plano de fondo.

- H4: la palabra y la música son elementos indispensables en la emisión del comentario deportivo.

- H5: los estilos expresivo y humorístico son los que adquieren un mayor protagonismo.

- H6: la figura del oyente aparece habitualmente en el discurso de este tipo de comentario.

- H7: la actualidad futbolística del día, los contenidos extradeportivos y los protagonistas referidos durante la emisión del programa, son los elementos temáticos más desarrollados.

- H8: cada emisora impone rasgos específicos al comentario deportivo en función de los objetivos y de la línea que caracteriza a los diferentes programas analizados.

\section{Metodología}

La estructura metodológica de la investigación se ha sostenido en base a la revisión de literatura y el análisis de contenido. El estudio de textos bibliográficos se constituye como el recurso más óptimo para conseguir una apropiada contextualización del tema que se aborda y una toma de conciencia del estado de la cuestión. De hecho, es clave a la hora de determinar los criterios sobre los que se estructura el análisis de contenido. La limitada presencia de estudios que existen sobre radio deportiva desde el punto de vista narrativo favorece la aplicación del método deductivo. El proceso consiste en la obtención de conclusiones aplicadas por un lado a las características del formato magacín deportivo, y por otro al concepto de género radiofónico y al análisis de los rasgos del comentario ya estudiado en investigaciones anteriores. 
Tras la finalización del marco teórico, en la siguiente fase se acomete el análisis de contenido de programas radiofónicos. Bardin, uno de los especialistas más consolidados en esta materia metodológica, lo define como aquel "conjunto de técnicas de análisis de comunicaciones que tiende a obtener indicadores (cuantitativos o no) por procedimientos sistemáticos y objetivos de descripción del contenido de los mensajes, permitiendo la inferencia de conocimientos relativos a las condiciones de producción/recepción (variables inferidas) de estos mensajes" (1986: 32).

Este método consiste en cuantificar ciertos elementos que aparecen en el texto con el fin de reconocer la predominante aparición de unos sobre otros. Los datos obtenidos traen consigo una serie de interpretaciones y conclusiones vinculadas a las variables estudiadas. En términos de Krippendorff, el análisis de contenido permite llevar a cabo "inferencias reproducibles y válidas que pueden aplicarse a su contexto" (1997: 28). Desde esta perspectiva epistemológica, el objetivo del investigador se centra en revelar sobre la superficie textual tanto lo potencial de los mensajes, como aquello no aparente de la expresión.

El análisis de contenido propuesto integra técnicas cualitativas y cuantitativas a través de las cuatro etapas o fases en las que se estructura: selección de variables, codificación, estudio estadístico y descriptivo, y contraste de resultados. La primera de ellas se lleva a cabo desde una perspectiva cualitativa, y consiste en la selección de los elementos de las unidades analizadas relacionadas con las hipótesis planteadas. Dichos elementos se asocian con el concepto de variables, entendiendo a estas como aquellos aspectos que pueden ser modificados en una investigación, y que "constituyen criterios o claves de significado para descubrir qué se dice y cómo se dice" (Piñuel y Gaitán, 1995: 534). Esta fragmentación de la realidad de corte positivista estructura el conjunto de ítems del protocolo de análisis.

Junto a la necesidad de que hagan referencia a características o propiedades observables de algo (o alguien), las variables se manifiestan como constructos susceptibles de presentar diferentes valores o categorías (Igartua, 2006: 135). Este es el objetivo de la segunda fase, en la que se elabora un sistema de categorías de contenido mediante un proceso inferencial vinculado al marco teórico desarrollado.

En la tercera fase se mide la frecuencia de aparición de las categorías planteadas para cada elemento. La aproximación al estudio estadístico y descriptivo del contenido de estos programas se constituye como la parte cuantitativa principal del análisis. Los rasgos que mejor definen esta etapa son la objetividad, y el énfasis puesto en lo sistemático y manifiesto. A continuación se exponen de manera exhaustiva los resultados obtenidos en el texto, y se extraen las inferencias y conclusiones al respecto.

El objetivo de la cuarta fase pretende contrastar los resultados obtenidos con las hipótesis planteadas. Según Orozco, la perspectiva cualitativa brinda al investigador interpretaciones a 
través de descripciones (1995: 78). Esta última etapa de carácter cualitativo se focaliza en torno a las características simbólicas y latentes del material que compone la muestra, a partir de lo cual se adquieren los criterios suficientes para verificar o refutar cada hipótesis.

Una vez expuestas las diferentes fases a seguir en el análisis de contenido, el siguiente paso consiste en explicar el procedimiento llevado a cabo para la selección de la muestra. Según Andréu, "las unidades de muestreo son aquellas porciones del universo observado que serán analizadas" (2000: 13). En la presente investigación estas unidades se corresponden con los magacines deportivos nocturnos de las principales emisoras privadas de carácter generalista: Cadena SER (El larguero), COPE (El partido de las 12), Onda Cero (Al primer toque) y Abc Punto Radio (Abellán en punto).

El periodo de tiempo en el que se integra la emisión de los programas analizados es enerodiciembre de 2012. Esta selección permite comprender parte de la temporada radiofónica 2011-2012 y de la 2012-2013, con el fin de poder estudiar los cambios y tendencias más importantes que se han producido en los últimos tres años naturales ${ }^{1}$ (2011, 2012 y 2013). La muestra queda configurada por 105 programas a partir de las 28 jornadas de emisión del año 2012, seleccionadas a partir del método de la "semana compuesta". De esta forma, se elige el lunes de la primera semana de enero, el martes de la segunda semana de febrero, y así sucesivamente hasta conseguir las cuatro semanas que equivalen a las 28 jornadas planteadas. Con este método se consigue que todos los meses y días de la semana formen parte de la muestra. El tamaño de la muestra es adecuado para llevar a cabo el estudio en profundidad de los distintos aspectos y variables que conforman el análisis, con el objetivo de contrastar las hipótesis planteadas.

Para llevar a cabo el análisis de estos programas se ha accedido a las webs de sus respectivas emisoras y se ha descargado los podcasts correspondientes (http://www.cadenaser.com/; http://www.cope.es/; http://www.ondacero.es/). En el caso del magacín Abellán en punto al dejar de emitir su cadena a comienzos del año 2013, los archivos de audio se han conseguido a través del audiokiosko digital Ivoox (http://www.ivoox.com/).

\section{Rasgos generales del magacín deportivo}

Conocido como programa "ómnibus", "contenedor" o de "variedades", el magacín generalista se ha consolidado en las últimas décadas como el espacio referente en el actual panorama radiofónico. Los datos de audiencia y su presencia masiva en las parrillas de programación de las emisoras generalistas avalan esta hipótesis. La definición de MartínezCosta y Díez Unzueta sintetiza los aspectos más característicos del formato: "programa de larga duración, emplazado en las franjas horarias importantes para la captación masiva de audiencia (...), dirigido por un/a conductor/a "estrella", con contenidos de actualidad, dotado de importantes equipos profesionales para la redacción, locución y producción, y que 
cuenta con una amplia presencia de colaboradores y expertos que enriquecen los contenidos del programa" (2005: 186).

A diferencia de los magacines generalistas emitidos en horario matinal que se alargan en antena hasta las cinco o seis horas, los programas especializados en deporte tienen una duración que oscila entre una hora y media y dos. Justo a continuación de los espacios "carrusel", el magacín de deportes emitido en la medianoche se ha consagrado como uno de los programas referentes en las principales emisoras convencionales. Checa considera que el magacín deportivo nocturno se ha convertido en "un desafío para todas las cadenas", especialmente en un contexto comunicativo caracterizado por la existencia de una intensa competencia y que obliga a los respectivos medios a incentivar la búsqueda de nuevas fórmulas que no siempre alcanzan el éxito (2005: 70).

La emisión en directo en este horario se consolida además como uno de los elementos que caracterizan la fórmula autóctona de este tipo de programa. Según Álvarez, su inserción en la franja de madrugada es "algo inexistente en el resto de modelos radiodifusores de otros países (2001: 246). Sin embargo, los contenidos deportivos emitidos a través del formato sports-talk radio en otros estados, presentan determinados aspectos de carácter narrativo estrechamente vinculados al formato español.

Este horario fomenta la presencia continua de contenidos de análisis y opinión sobre la actualidad deportiva del día, ya que son muy numerosas las fuentes de información de las que dispone el oyente para conocer de forma inmediata lo acontecido durante la jornada (entre ellas, Internet). Esta heterogeneidad estética y de contenido, tal como sostienen MartínezCosta y Díez Unzueta, hace que la opinión se acumule con la información, las entrevistas se sucedan entre tertulias, y los tonos radiofónicos manejen toda la gama posible de registros (2005: 189).

Durante la primera década del siglo XXI este espacio ha tratado de dotar un importante dinamismo a sus emisiones, tomando como eje principal la creación de un ritmo elevado y estilo narrativo variado. Se trata, por tanto, de adecuar el plano formal y de contenido a cada momento del programa, con el objetivo de conseguir elaborar un producto final ágil y cercano en base a una importante acumulación de voces y protagonistas y la mezcla de géneros. Los magacines deportivos, salvo excepciones, tienden a evitar secciones excesivamente largas y no se limitan al uso exclusivo de monólogos y entrevistas en profundidad, rasgos que definieron a este formato durante las décadas de los ochenta y parte de los noventa con José María García como figura referente.

González Conde considera la palabra como elemento fundamental del magacín, y afirma que "las secciones son principalmente habladas y en ellas se cultivan géneros como la entrevista, el reportaje, la tertulia, la participación de oyentes, etc.” (2001: 267). La radio es el medio por excelencia de la palabra, sin duda el proceso de comunicación más rápido e inmediato, 
mientras que uno de los aspectos que mejor definen a este medio en la actualidad es su carácter conversacional, coloquial y cercano al oyente. Susana Herrera afirma que "el discurso programático ha experimentado una fuerte tendencia hacia la reproducción de formas discursivas muy cercanas al prototipo de las interacciones verbales cotidianas que tienen lugar entre los hablantes" (2004: 336). La naturaleza dialógica se ha consolidado como uno de las piezas claves de los espacios deportivos en la actualidad, asociándose con el fenómeno del talk-show y el espectáculo del habla.

Ortiz y Marchamalo se basan en las conclusiones de Merayo para afirmar que el diálogo aporta a la narración radiofónica, "proximidad psicológica, credibilidad, atención y eficacia" (1997: 123). A partir de este contexto comunicativo, el conductor del programa y sus colaboradores se encargan de dotar de un estilo personal a cada espacio, ajustando en cada momento el ritmo del mismo y marcando las pautas según los objetivos planteados en un principio.

Una de las tendencias que caracteriza el actual panorama de radio deportiva es la búsqueda de estrategias comunicativas más distendidas, sustentadas en el carácter informal de las emisiones y la presencia de contenidos de humor. Paniagua señala que estos programas están "constantemente salpicado de bromas y guiños a los oyentes", a diferencia de lo que ha ocurrido en décadas pasadas en las que predominaba más el tono serio, dogmático y de denuncia (2009: 38). De este modo, se consigue un estilo más natural y próximo al oyente, al tiempo que la información y la opinión se complementan con el espectáculo radiofónico. Una de las figuras que han consolidado este estilo de conducción es José Ramón de la Morena a través de su programa El larguero (Cadena SER), modelo a imitar desde que a mediados de los años cincuenta alcanzara el liderazgo en audiencia.

En cuanto a los contenidos se refiere, hay que destacar el protagonismo de la materia futbolística, así como la integración progresiva que se alejan de la realidad estrictamente deportiva (explotando para ello las múltiples dimensiones y dimensiones con las que se vincula el deporte en la sociedad actual).

\section{Conceptualización y clasificación de los géneros radiofónicos}

El género radiofónico se relaciona con el modelo de enunciación que consolida la estructura formal del relato en función de los diferentes elementos que definen la naturaleza de este medio de comunicación. El canal elegido no es un simple portador de señales, ya que se trata de un verdadero código de comprensión cultural reconocido por emisores y receptores. En esta línea, Merayo asocia el género en radio "cada uno de los modos de armonizar los distintos elementos del lenguaje radiofónico -especialmente la palabra- de manera que la estructura resultante pueda ser reconocida como perteneciente a una modalidad característica de la creación y difusión radiofónica" (1992: 173). Estos rasgos constructivos dotan de identidad y personalidad a los diferentes mensajes emitidos, al tiempo que configuran una 
serie de expectativas que facilitan la interacción de los actores implicados en el proceso comunicativo.

La elección de un género u otro depende de los objetivos planteados en cada caso. El emisor puede tratar de informar o interpretar, optar por incorporar ideas o, por último, entretener o persuadir, lo que a su vez permite distinguir cuatro tipos de géneros: informativos, de opinión, entretenimiento y persuasión (Rodero, 2005: 191). No obstante, autores como Wolf asocian el género radiofónico con un conjunto heterogéneo de propiedades textuales e intertextuales, lo que dificulta su definición partiendo exclusivamente de las intenciones de los emisores o los efectos producidos en el oyente (1984: 189). El tipo de discurso predominante (narración, descripción, exposición y argumentación) y la forma expositiva con la que se desarrollan en cada momento, son dos de los aspectos que tradicionalmente han intervenido en la construcción de su concepto.

Las variantes de algunos géneros dificultan delimitar con exactitud las fronteras existentes entre unas y otras estructuras. Tal como señaló Cebrián Herreros hace ya más de dos décadas, los géneros tienden a mantener entre sí una estrecha relación de proximidad (1992: 25). En la práctica no suelen aparecer en estado puro, ya que las fronteras son ambiguas y las aproximaciones acaban materializándose en trasvases. Al respecto, hay que destacar la continua presencia de contenidos de opinión en géneros teóricamente informativos.

Este último aspecto es una de las claves que definen en líneas generales el actual panorama radiofónico, y específicamente, la naturaleza de los programas deportivos. Martínez-Costa y Herrera afirman que "nos encontramos con que el clásico criterio de agrupar los géneros en torno a la información o a la opinión deja fuera muchas de las reflexiones ya defendidas en torno a que todo el periodismo es interpretación y representación subjetiva de la realidad" (2008: 4). Todos estos factores han provocado que exista una amplia disparidad de criterios a la hora de establecer los parámetros necesarios para su clasificación.

Los primeros intentos de ordenación de las estructuras narrativas radiofónicas en España experimentan una importante influencia procedente de la prensa escrita, al tiempo que tienden a dejar al margen de dichas tipificaciones los géneros predominantemente de opinión. Uno de los primeros investigadores que introduce estas últimas estructuras en su clasificación es Cebrián Herreros. Su criterio de catalogación se sostiene en la actitud que mantiene el autor frente a la realidad. De esta forma, distingue tres formas esenciales de aproximarse al acontecimiento sucedido que, a su vez, se materializan en tres modos de representación (1992: 355 y ss.):

1) Desde adentro hacia afuera: situación anímica interpretativa o de opinión personal, que se manifiesta mediantes modos de configuración expresivos). Cebrián Herreros asocia los géneros expresivos o testimoniales con el ofrecimiento de una concepción y 
configuración personal del autor respecto de la realidad: editorial, comentario, crítica y crónica.

2) Desde fuera hacia adentro: se origina en una realidad exterior al usuario para producir posteriormente modos de configuración referenciales. Los géneros referenciales o expositivos se definen por ofrecer una visión distanciada de los hechos, orientando la narración o descripción tanto sobre sucesos comprobables como de ideas u opiniones ajenas: noticia, reportaje, informe periodístico, documental y docudrama.

3) Actitud dialógica: que se traduce en modos de configuración apelativos. Los géneros apelativos o dialógicos permiten profundizar en el pensamiento, acciones y sentimientos de los demás. Se orientan, por tanto, a la exposición de hechos, ideas u opiniones de aquellas personas que tienen información y opinión. Si bien los géneros expresivos y referenciales se estructuran a partir del monólogo, este tercer grupo se define por el intercambio y la confrontación de opiniones en relación a la formulación de preguntas e interacciones entre dos o más voces: entrevista, encuesta, rueda de corresponsales y emisoras, mesa redonda, debate, tertulia y géneros de participación.

Otra de las clasificaciones de géneros informativos y de opinión más empleadas en la actualidad es la expuesta por Merayo y Pérez (2001: 153). Estos autores distinguen los diferentes géneros existentes en base al tipo de discurso empleado (narrativo, descriptivo, expositivo y argumentativo), y la forma de comunicación utilizada (monólogo-mixtodiálogo). La complejidad que trae consigo la integración de criterios formales y de contenido como ámbitos de clasificación, se añade a la ausencia de variables descriptivas en dicha tipología. Se observa cómo estos autores se centran exclusivamente en los géneros informativos, dejando a un margen el resto de estructuras existentes en el actual panorama radiofónico (ficción, entretenimiento y publicidad) (v. tabla 1).

Tabla 1. Tipos de discurso y géneros radiofónicos de Merayo y Pérez

\begin{tabular}{|c|c|c|c|}
\hline Tipo de discurso & $\begin{array}{l}\text { Géneros de } \\
\text { monólogo }\end{array}$ & Géneros mixtos & $\begin{array}{l}\text { Géneros de } \\
\text { diálogo }\end{array}$ \\
\hline Narrativo & Noticia & \multirow{4}{*}{ Reportaje } & Noticia dialogada \\
\hline Narrativo-Descriptivo & $\begin{array}{l}\text { Noticia } \\
\text { Informe }\end{array}$ & & $\begin{array}{l}\text { Noticia dialogada } \\
\text { Entrevista }\end{array}$ \\
\hline Descriptivo & $\begin{array}{l}\text { Noticia } \\
\text { Informe }\end{array}$ & & Entrevista \\
\hline $\begin{array}{l}\text { Descriptivo-Expositivo } \\
\text { Expositivo }\end{array}$ & $\begin{array}{l}\text { Informe Crónica } \\
\text { Editorial } \\
\text { Comentario }\end{array}$ & & $\begin{array}{l}\text { Entrevista } \\
\text { Coloquio } \\
\text { Participación }\end{array}$ \\
\hline
\end{tabular}




\begin{tabular}{|l|l|l|} 
Expositivo-Argumentativo & $\begin{array}{l}\text { Editorial } \\
\text { Comentario }\end{array}$ & \\
\hline Argumentativo & & \\
\hline
\end{tabular}

Fuente: Martinez-Costa y Herrera Damas (2004)

\section{Aspectos narrativos y discursivos del comentario}

El comentario radiofónico emplea la forma de monólogo para analizar y emitir juicios de valor de forma individual (no institucional). A través de una estructura simple y de escasa duración, Martínez-Costa y Díez Unzueta consideran que este género se constituye como una mirada diferente a cierta distancia que permite observar la realidad en su conjunto (2005: 110). Se trata de valoraciones vinculadas con la información y actualidad del momento, con el objetivo de emitir un discurso de naturaleza fundamentalmente argumentativa en el que adquieren un especial protagonismo la función ornamental y el estilo personal de cada autor.

El concepto de comentario se vincula con la emisión de una serie de argumentos lógicos y verosímiles a favor de una conclusión o tesis. Plantin considera que la argumentación se sostiene sobre un enunciado aceptado generalmente con el fin de apoyar otro menos asegurado y aceptado que es la conclusión (1998: 39). La aplicación de los procedimientos argumentativos requiere la elección de una estructura determinada, así como el uso de recursos lingüísticos específicos acorde a los propósitos establecidos en un principio. En la redacción escrita se distinguen varios tipos de argumentos diferentes, los cuales se pueden aplicar al discurso radiofónico:

- De autoridad: cuando se apoya en testimonios fidedignos de personalidades famosas y expertas en la materia (Álvarez, 1999: 31).

- Mediante el ejemplo: cuando se alude a la experiencia compartida entre autor y receptor (Ibídem: 37-38).

- De experiencia personal: se estructura a partir de una experiencia vivida por el emisor o transmitida a este por otra persona.

- Por analogía: si la argumentación discurre de un caso o ejemplo específico a otro aludiendo a su semejanza.

- De universalidad: sostenido en el peso moral que tiene lo generalmente aceptado.

- De las causas: explica por qué sucede alguna cosa en base al origen de la misma.

- Deductivo: si la verdad de sus premisas garantiza la verdad de sus conclusiones.

El discurso argumentativo en sentido clásico está estrechamente vinculado con la posibilidad de influir en el otro como funciones básicas. Este concepto de persuasión es definido por Spang a través de los siguientes términos: "capacidad de influir en la psique y la voluntad de 
los oyentes para hacerles cambiar de opinión consiguiendo también que actúen de una forma determinada" (2005: 83).

El comentario tiende a ser producido y leído por un profesional de prestigio y experiencia. Santamaría afirma que una de las características del periodismo moderno es la tendencia a que el comentario firmado desplace al anónimo institucional, ya que lo personal y firmado tiene un mayor interés que lo anónimo y colectivo (1990: 118). La figura de este autor se asocia con la manifestación explícita del sujeto de enunciación mediante la creación de un discurso subjetivo de focalización interna y al mismo tiempo con la del narrador omnisciente, ya que su opinión se consolida como aspecto clave y relevante del género (Guarinos, 2009: 202).

La autoría del comentarista se materializa a través de diferentes mecanismos, que van desde la elección del tema en la fase de ideación hasta la elección de los elementos sintácticos y figuras retóricas empleadas en su desarrollo textual. Martínez-Costa y Herrera distingue las siguientes formas mediante las cuales el autor del comentario puede participar en el texto (2008: 8):

1) Escoger el tema.

2) Definir su postura.

3) Seleccionar los argumentos para la defensa de su postura.

4) Elegir las figuras retóricas que considere más oportuno.

5) Destacar los refranes, ejemplos y proverbios que estime adecuado como elementos auxiliares que refuerzan sus argumentos.

6) Seleccionar los elementos sintácticos para la construcción del cuerpo argumentativo.

Este tipo de género radiofónico tiende a tratar contenidos relacionados con la actualidad y los temas del día, si bien no está sometido a la urgencia e inmediatez de otras estructuras informativas como la noticia. Más allá de opinar sobre un acontecimiento que acaba de suceder, el comentario persigue aportar elementos de juicio sobre temas de interés conocidos por los oyentes y que no pasan desapercibidos para la mayoría de estos.

La brevedad de este género hace que en su desarrollo el tema referente al que aluda no sea presentado con excesivos detalles con el fin de extenderse en la exposición de los argumentos. Según Martínez-Costa, "muchas veces los argumentos y la conclusión que se presente destacarán aspectos accidentales o secundarios, sin centrarse en el proceso ni profundizar en sus causas o consecuencias" (2008: 10). En este sentido, el comentario de cada jornada se puede entender como una parte de la visión y estilo global de su autor y que el receptor habitual irá configurando al tiempo que fideliza su escucha. 
En cuanto a su estructura, destaca el esquema cerrado que toma como base la presentación de la retórica clásica (Merayo, 2002: 90):

1) Introducción: presentación de un hecho de actualidad mediante referencias a elementos menores, accidentales o anecdóticos con el fin de llamar la atención de la audiencia.

2) Mención inmediata del tema central: para facilitar la identificación y escucha del receptor.

3) Breve desarrollo de los argumentos.

4) Conclusión: en forma de hipótesis de futuro o planteando una petición o demanda, pero siempre a través de un estilo expositivo claro y conciso.

La mayoría de comentarios que se emiten hoy en la radio generalista española se llevan a cabo a partir de una estructura deductiva que va de lo general a lo particular, de la conclusión a los argumentos (Martínez-Costa y Herrera, 2008: 17). A pesar de que también se puede seguir la fórmula inductiva, la primera de éstas facilita la comprensión del contenido desarrollado con respecto a la audiencia.

A pesar de la gran libertad que admite el comentario, la palabra es el elemento protagonista del lenguaje radiofónico. La música, los efectos sonoros y el silencio apenas aparecen en este tipo de género, al tiempo que limitan su presencia en relación a las funciones de realización (Merayo y Pérez, 2001). El mayor o menor grado de expresividad del comentario se relaciona con los elementos estilísticos, retóricos y argumentativos con los que materializa el contenido textual el autor del mismo. Algunas de estas constantes que se repiten más habitualmente en el comentario son (Martínez-Costa y Herrera, 2008: 14-15): la concisión y la brevedad que determina la concentración de los argumentos, la variedad de registros de las que dispone el comentarista en función del contexto comunicativo, la diversidad léxica que puede traer consigo nuevos términos, la creación de archisílabos o la utilización de diminutivos y acortamientos, la utilización del lenguaje metafórico, el empleo del recurso de la ironía, el uso del humor o las apelaciones directas a los receptores, entre otras².

\section{Resultados y discusión}

El comentario es el quinto género radiofónico que cuenta con una mayor presencia de tiempo acumulado en la muestra seleccionada, aunque con un porcentaje $(1,65 \%)$ muy inferior en comparación con el de las estructuras estrella del programa: la entrevista, la tertulia y la noticia (v. gráfico 1). Este género aparece en el 45,71\% del total de programas analizados, especialmente durante las jornadas de lunes a jueves y domingos consolidándose como una sección diaria más. De los 48 comentarios hallados en la muestra, sólo 4 son emitidos los viernes y sábados. En estos dos últimos días los datos de audiencia disminuyen, los principales presentadores y colaboradores del programa son sustituidos por otros 
miembros de la redacción, y los contenidos y enfoques del espacio presentan importantes cambios con respecto a la emisión del resto de la semana.

\section{Gráfico 1. Tiempo acumulado de los principales géneros radiofónicos}

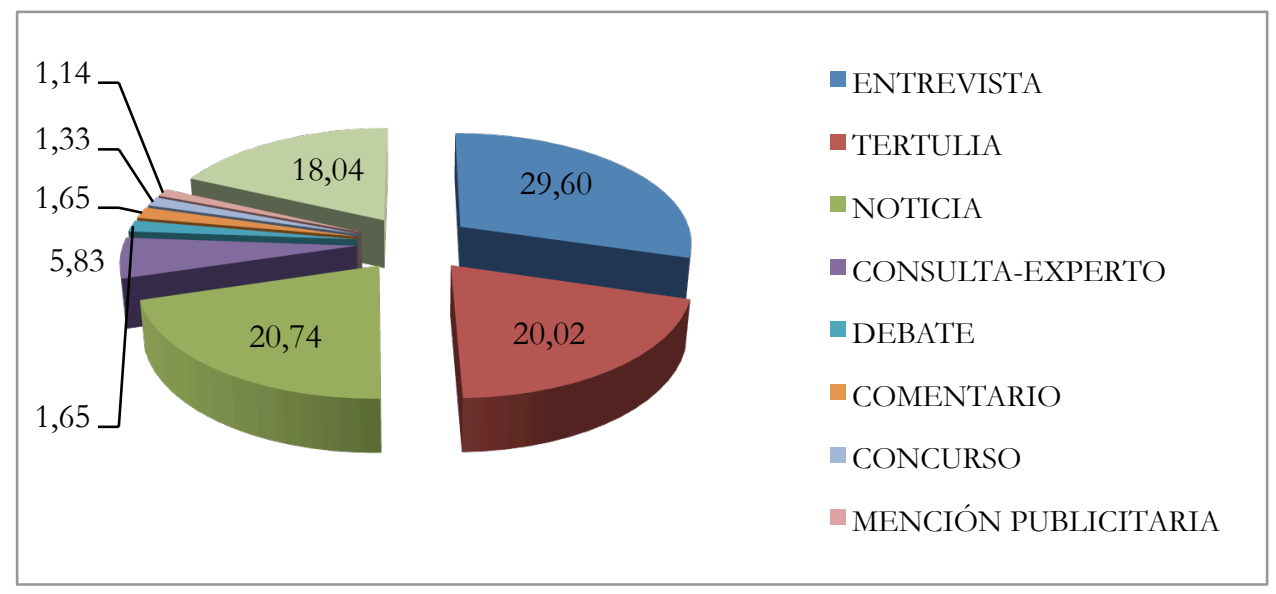

Fuente: elaboración propia

Abc Punto Radio es la emisora que introduce un mayor número de este tipo de estructuramonólogo (16), mientras que Onda Cero es la que menos (4). Este último medio introduce cambios en la dirección del programa Al primer toque durante el año 2012. Si bien durante los primeros meses el comentario no aparece en ninguna ocasión, a partir de septiembre con la llegada de Héctor Fernández comienza a tener una mayor presencia. Por su parte, la Cadena SER, emisora que tradicionalmente ha seleccionado este género radiofónico como sección diaria de su magacín El larguero, y COPE, alcanzan ambas la cifra de 14 comentarios.

Su duración media es de 03:00 minutos aunque también depende del medio en cuestión: la Cadena SER opta por el formato más breve (01:47) y Abc Punto Radio por el más extenso (04:36). En todos los casos analizados la ubicación del comentario se produce en los momentos finales del magacín deportivo, lo que se constituye como uno de los rasgos más característicos de su identidad. Asimismo, no se han hallado espacios en los que se emita más de una unidad durante una misma jornada de emisión.

El comentario se basa en la elaboración y posterior lectura de un texto de opinión por parte de algún colaborador específico del programa. En el mismo se combina las impresiones de su autor con importantes dosis de creatividad y expresividad. En el magacín El partido de las 12 (COPE) es Pepe Domingo Castaño la voz principal del comentario. Su larga trayectoria profesional y experiencia en la radio deportiva lo convierten en una figura muy respetada entre sus oyentes. En la emisión del 19-01-2012 el presentador del programa da paso a Castaño refiriéndose a su comentario como "la mejor parte del programa". En Alprimer toque (Onda Cero) es un joven profesional de la emisora, Jordi Gosalvez, conocido por su humor y peculiar punto de vista a la hora de analizar la actualidad deportiva de cada día. En El larguero 
(Cadena SER) y Abellán en punto (Abc Punto Radio) los encargados del comentario proceden de otros medios de comunicación: Juanma Trueba (diario As) y Miguel Ángel Sevilla (cantante y showman televisivo), respectivamente.

La variable temporal asociada a su forma de emisión pone de manifiesto una importante homogeneidad entre los diferentes magacines analizados. Todos los comentarios de la muestra son emitidos en directo o falso directo, sin llegar a incorporar ningún corte de voz. El espacio sonoro que adquiere más protagonismo se relaciona con el primer plano, mientras que el plano de fondo está estrechamente relacionado con los elementos musicales. La palabra se consolida como el recurso del lenguaje radiofónico protagonista de este género radiofónico, al tiempo que los efectos sonoros y los silencios no aparecen en ningún caso.

El comentario mantiene numerosos vínculos con la música. En todas las unidades analizadas aparece este recurso del lenguaje radiofónico realzando la palabra, si bien puede cumplir diferentes funciones: identificativa (58,33\%), ornamental (33,33\%) y referencial $(14,58 \%)$ (v. gráfico 2).

En tres de los cuatro medios analizados la emisión del comentario aparece habitualmente con un mismo contenido musical de fondo, facilitando la identificación de dicha estructura por parte de la audiencia (58,33\%). Los temas de la COPE y Cadena SER son instrumentales y evocan una atmósfera emocional de gran sensibilidad, lo que consigue atraer la atención de los receptores. Avanzada la madrugada y con el oyente en duermevela, el comentario se entiende como una forma diferente y relajada de repasar las sensaciones que ha deparado la actualidad deportiva del día ${ }^{3}$. Sirve como ejemplo el tema emitido en El partido de las 12 perteneciente a la banda sonora Once Upon A Time In The West (Ennio Morricone). Onda Cero opta por un tema instrumental más ameno con el objetivo de complementar el carácter distendido del texto locutado.

Gráfico 2. Las funciones de la música en el comentario deportivo

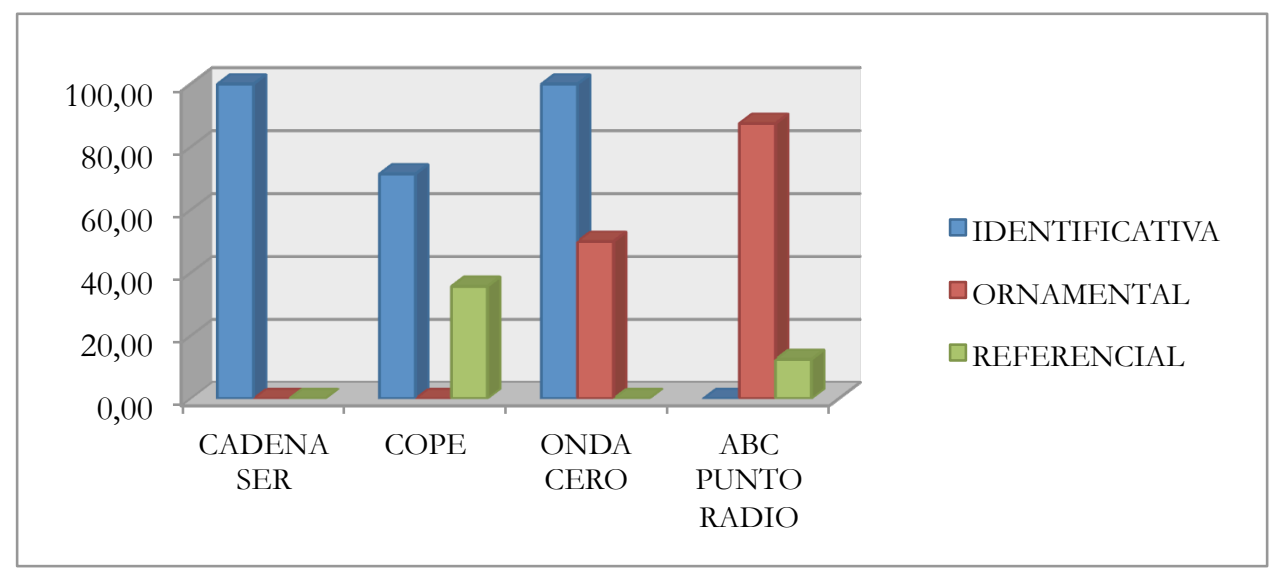

Fuente: elaboración propia 
El resto de elementos musicales seleccionados varían cada jornada y pueden cumplir dos funciones principalmente: ornamental y referencial. La primera de éstas, también conocida como atrezo auditivo, consigue dotar de un mayor dinamismo a este género radiofónico aunque su presencia no guarda relación alguna con la temática del día y su aporte significativo es menor.

La música referencial depende del contenido desarrollado en el propio comentario. Es el caso del tema de la cantante Whitney Houston que aparece en el magacín Abellán en punto en la emisión del 14-02-2012 como consecuencia de su reciente fallecimiento. En la cadena COPE destaca el comentario que realiza el colaborador Pablo Sudoku a modo de canción durante los viernes y ciertas emisiones de los domingos. La originalidad de este tipo de comentarios reside en la composición de la letra, al ritmo y son de una base musical de rap diferente para cada ocasión.

El estilo expresivo es el que adquiere un mayor protagonismo en todos los comentarios analizados $(83,33 \%)$, seguido a continuación del tono desenfadado (6,25\%), irónico (4,17\%), neutro $(2,08 \%)$, emotivo $(2,08 \%)$ y crítico $(2,08 \%)$. El lenguaje directo queda en un segundo plano con el objetivo de que los juegos retóricos y las pretensiones literarias se conviertan en elementos claves de este género en el magacín deportivo (v. gráfico 3). Sirvan como ejemplos las siguientes frases halladas en el magacín El partido de las 12 del día 19-01-2012: "Es la magia de esta Sevilla a la que he ido aprendiendo a querer como el poeta, verso a verso, feria a feria, derbi a derbi, fino a fino", "El uno todavía con las marcas que tuvo al cuello y que nadie se atrevió a apretar por si la pasta gansa" o "El otro, cual bombero sin casco y sin manguera, intentando apagar con más palabras que hechos los incendios diarios de grada y de plantilla". La única excepción se encuentra en Onda Cero, donde el estilo irónico y distendido se impone al expresivo.

\section{Gráfico 3. Estilo enunciativo del comentario deportivo}

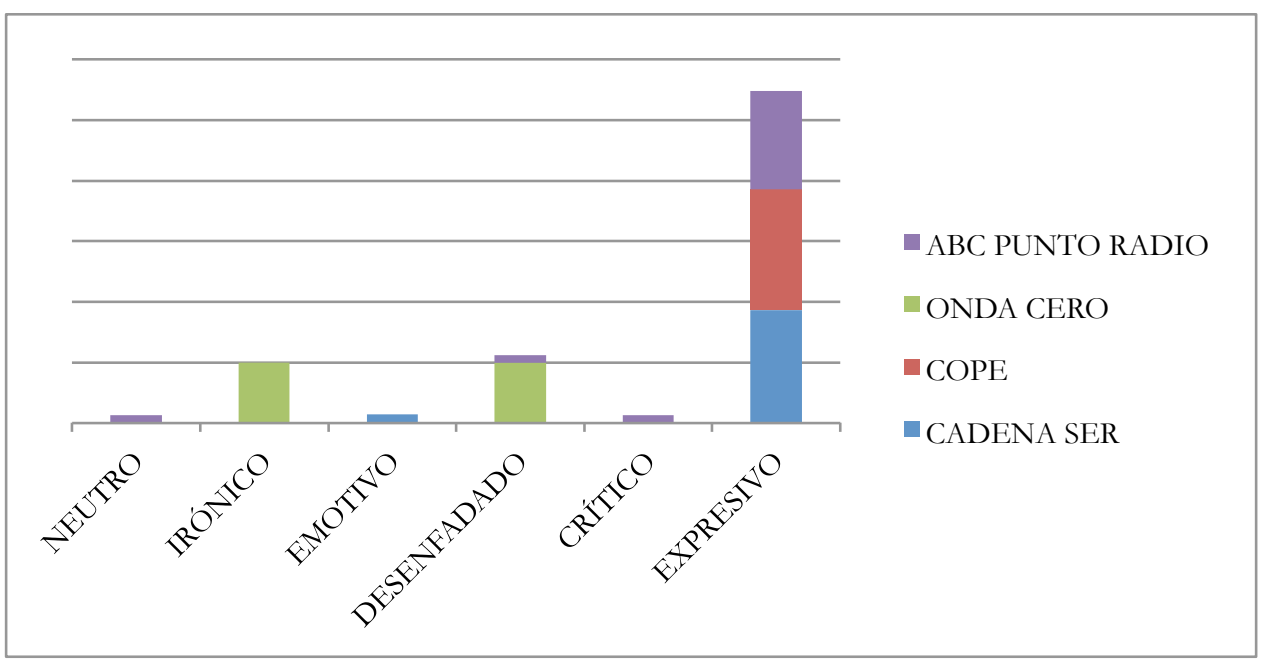

Fuente: elaboración propia 
En cuanto a la representación de la figura de los oyentes, destaca la ausencia de homogeneidad entre los cuatro medios seleccionados (v. gráfico 4). Una de las tendencias más significativas en el actual panorama radiofónico consiste en dotar de un mayor protagonismo al receptor con el objetivo de que éste se sienta partícipe de la emisión que escucha. La audiencia aparece referida en los textos del comentario en el 16, 67\% de los casos analizados, si bien el porcentaje es notablemente superior en Onda Cero (50\%) e inferior en Abc Punto Radio (6,25\%). Algunos ejemplos de estas apelaciones son: "os voy a contar un secreto", "no se me preocupen", "iy tú te lo crees!", "para que me entiendan", "señores, pues vamos a terminar" o "una jornada que ya saben...". No se ha encontrado ninguna mención a oyentes específicos ya que todas van destinadas al conjunto plural e indefinido de la audiencia.

Las referencias a contenidos relacionados con la actualidad deportiva procedentes de las redes sociales (Facebook y Twitter, principalmente) han adquirido una especial relevancia en los programas radiofónicos de deporte durante los últimos años. No obstante, el comentario apenas incorpora este elemento en su emisión, ya que sólo en un comentario de Abc Punto Radio se han hallado menciones a este tipo de medios.

\section{Gráfico 4. Las apelaciones a los oyentes en el comentario deportivo}

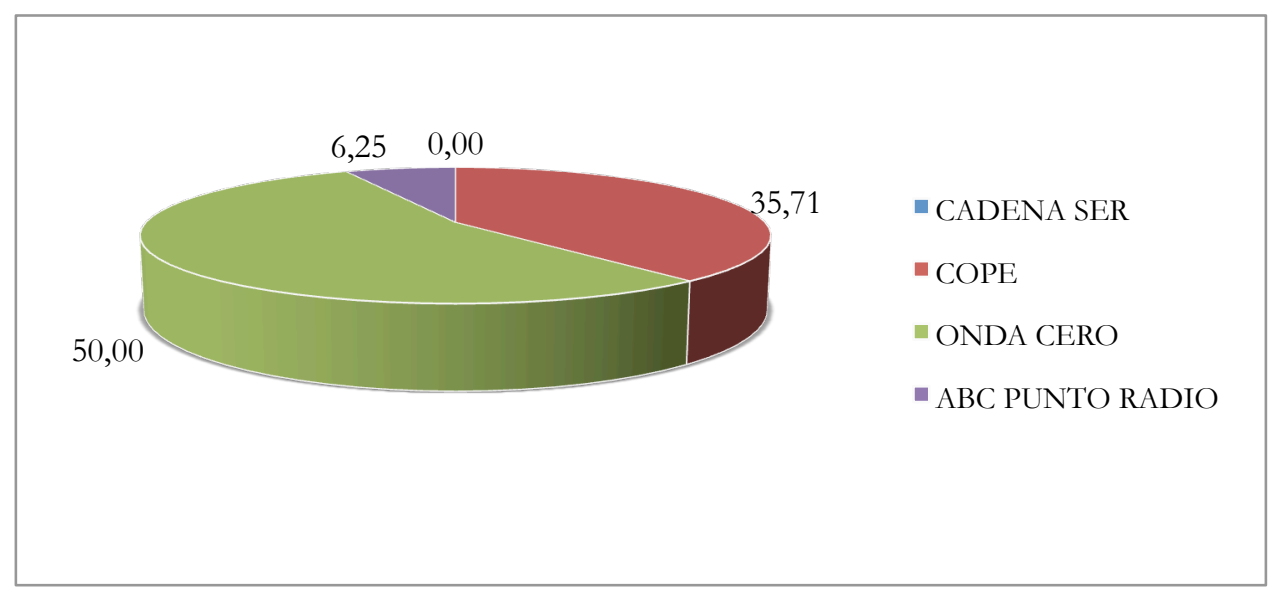

Fuente: elaboración propia

A excepción de Abc Punto Radio - un único tema por unidad-, el comentario suele incluir la valoración de varios contenidos o acontecimientos en cada emisión. No obstante, en el $85,42 \%$ de las ocasiones analizadas solo se alude a la materia futbolística. Este aspecto se ha consolidado como sello de identidad de la radio deportiva y de forma más específica, de la casi totalidad de géneros radiofónicos que integran el formato magacín. En el caso específico de la Cadena SER, este porcentaje disminuye debido a que el fútbol comparte protagonismo con otras disciplinas deportivas en el 35,71\% de los casos (tenis, baloncesto, automovilismo, motociclismo y ciclismo, entre otras). En el magacín de COPE y con menor relevancia en el 
programa de la Cadena SER, el análisis de la actualidad se estructura a partir de las referencias a los personajes que de una forma u otra han sido protagonistas en la emisión de dichos espacios.

La dimensión temporal de los eventos deportivos desarrollados se vincula con el presente en el $66,67 \%$ del total de comentarios hallados en la muestra, es decir, que han tenido lugar durante el mismo día de la emisión o bien una jornada antes o después (v. gráfico 5). A continuación el tiempo que adquiere un mayor protagonismo es el pasado (12,50\%), englobando a aquellos acontecimientos o noticias de deporte que se han producido dos o más días antes. El tiempo futuro (dos o más jornadas después) no se ha detectado en ninguna de las unidades analizadas.

\section{Gráfico 5. La dimensión temporal de los contenidos en el comentario deportivo ${ }^{4}$}

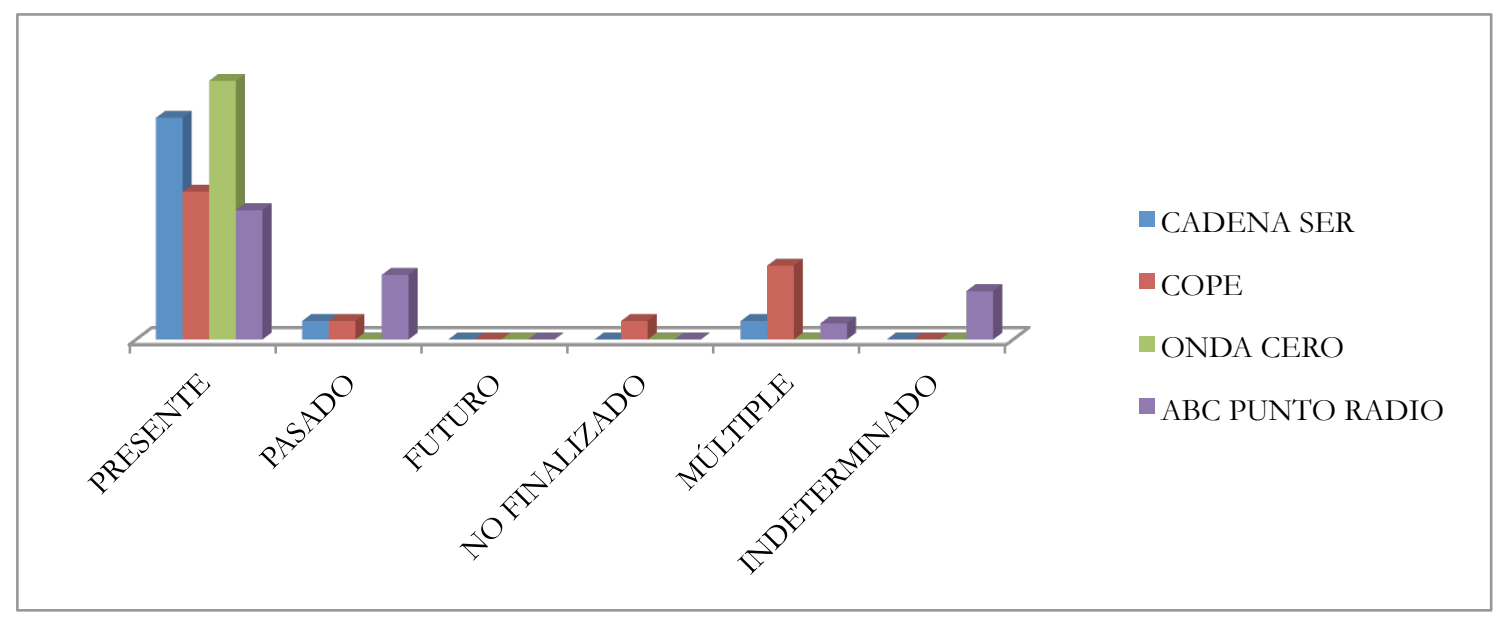

Fuente: elaboración propia

Se observa la presencia de contenido extradeportivo en la mitad de los comentarios analizados de la muestra. Este aspecto se distribuye de forma irregular en función de la emisora seleccionada, alcanzando una varianza de hasta 50 puntos entre la que menos referencia hace a estos contenidos (Cadena SER-7,14\%) y la que más (Onda Cero-100\%).

La dimensión extradeportiva que más relevancia adquiere en la muestra es la económica $(33,33 \%)$, la cual está estrechamente vinculada con las cifras que se mueven en torno al mercado de traspasos de futbolistas (v. gráfico 6). Posteriormente, el contenido social $(16,67 \%)$ está presente en aquellos comentarios en los que se menciona alguna noticia social o cultural con cierta repercusión en el momento de la emisión del programa (personajes públicos, desastres naturales, espectáculos televisivos o musicales, etc.). Apenas se han encontrado alusiones a contenidos políticos, si bien esta variable temática incluye un amplio abanico de acontecimientos de diferente índole. Sirve como ejemplo el comentario emitido 
en Abellán en punto el 10-10-2012, dedicado de modo íntegro a unas fotos de la vida privada del entrenador de fútbol Unai Emery.

Gráfico 6. Las dimensiones extradeportivas en el comentario deportivo

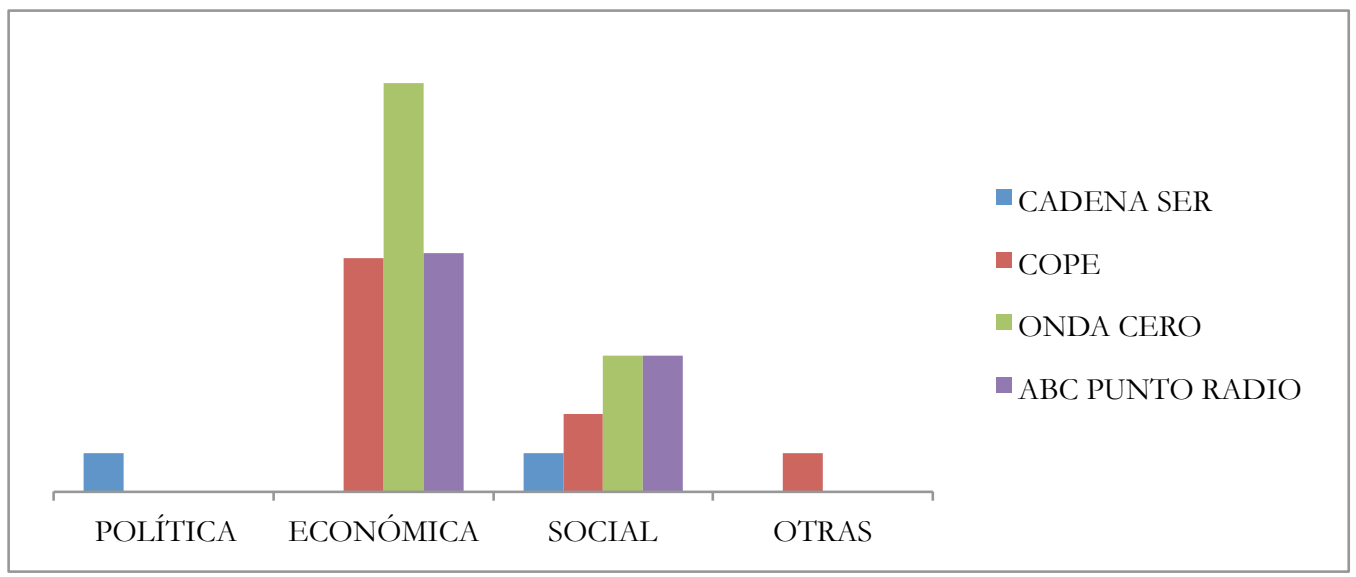

Fuente: elaboración propia

A continuación se transcriben cuatro fragmentos de comentarios emitidos en cada uno de los programas seleccionados con el objetivo de sintetizar los aspectos más destacados observados en la muestra.

En la transcripción 1 el contenido del comentario se relaciona con las polémicas declaraciones que el futbolista Cristiano Ronaldo había realizado el mismo día de la emisión del programa. Esta noticia es desarrollada durante gran parte del magacín, como se indica en el texto cuando su autor alude a la entrevista que han realizado al exfutbolista Paulo Futre. La principal diferencia está en el enfoque más reposado, reflexivo y argumentativo del comentario, a diferencia de lo que ocurre en el resto de géneros. En este caso concreto la estructura del comentario sigue la línea tradicional de introducción ("El comunicado de Cristiano alimentó el culebrón"), mención del tema ("el futbolista asegura que su problema no es monetario"), desarrollo de argumentos ("Cristiano esperaba ganar el premio" o "parece claro que le fallan los asesores") y conclusiones (la obsesión del futbolista con Leo Messi). 


\begin{tabular}{|c|c|c|}
\hline VOZ & PARLAMENTO & $\begin{array}{l}\text { OTROS } \\
\text { SONIDOS }\end{array}$ \\
\hline $\begin{array}{l}\text { Juanma } \\
\text { Trueba }\end{array}$ & $\begin{array}{l}\text { El comunicado de Cristiano alimentó el culebrón que nos entretiene el parón } \\
\text { liguero. El futbolista asegura que su problema no es monetario y que no pretende } \\
\text { una mejora en su contrato. De ser cierto y no tenemos por qué dudarlo, Cristiano } \\
\text { sólo reclama cariño y atenciones, cuestiones en las que también pensábamos que } \\
\text { era millonario. Acudimos a Futre para que nos ayudara a entender el caso un } \\
\text { poco mejor. Según él, Cristiano esperaba ganar el premio que le dieron a Iniesta, y } \\
\text { a partir de ahí se genera todo el problema. Que si el club no le apoya, que si el } \\
\text { equipo no le hace campaña... No podemos decir si a Cristiano le falla la cabeza o } \\
\text { la madurez, pero parece claro que le fallan los asesores. Quienes debieran ser sus } \\
\text { consejeros actúan según parece como palmeros, probablemente porque piensan } \\
\text { más en la comisión que en el bienestar de su cliente. La comparación con Messi } \\
\text { no es periodística, es personal. Cristiano y su entorno persiguen a Messi con } \\
\text { tanta obsesión que han terminado por creer que la diferencia entre ambos es una } \\
\text { simple cuestión de marketing [...]. }\end{array}$ & $\begin{array}{l}\text { Música } \\
\text { identifica- } \\
\text { tiva en } \\
\text { plano de } \\
\text { fondo }\end{array}$ \\
\hline
\end{tabular}

Fuente: elaboración propia

A diferencia de lo que ocurre en el ejemplo anterior, en la transcripción 2 se tratan varios contenidos de actualidad aunque todos relacionados con la disciplina futbolística. A ello se añaden dos breves menciones a contenidos extradeportivos como introducción del comentario: la meteorología y las elecciones en Asturias y Andalucía. En esta ocasión las estrategias argumentativas no están tan desarrolladas. Su principal atractivo reside en el poder retórico del texto a la hora de sintetizar en una o dos frases los diferentes acontecimientos tratados: "El fútbol repite mayúsculas de asombro" (el nuevo galardón entregado al futbolista Leo Messi), "enfrascado en esa tarea subterránea de decir lo que no piensa" (declaraciones del entrenador Pep Guardiola) o "casi todos los equipos deshojan sus propias margaritas mirando al frente" (en referencia a la incertidumbre de las últimas jornadas de competición en las que los clubes se juegan definitivamente los objetivos de la temporada). 
Transcripción 2. E1 comentario deportivo en la cadena $\mathrm{COPE}^{6}$

\begin{tabular}{|lll|}
\hline VOZ & PARLAMENTO & OTROS \\
\hline & & SONIDOS \\
\hline & Las jornadas de Liga entre semana se cuelan un poco a contracorriente en el & \\
& aluvión de noticias que va generando el calendario. Por un lado, la meteorología & \\
Pepe & que recupera el rostro serio y frío del invierno. Por otro, los redobles electorales & Música \\
Domingo & que anuncian urnas calientes en Asturias y Andalucía. El fútbol repite mayúsculas & identifica- \\
& de asombro ante la consagración definitiva de Messi como señor de los balones. & tiva en \\
& Guardiola mira de reojo los números pendientes enfrascado en esa tarea & plano de \\
& subterránea de decir lo que no piensa, aunque suponemos que ahora habrá & fondo \\
& cambiado de opinión. Mientras casi todos los equipos deshojan sus propias & \\
& margaritas mirando al frente, aparecen los horarios de las jornadas que nos & \\
& llevarán al cogollo de la primavera. Alguien sigue empeñado en rizar todos los & \\
& rizos del despropósito a la hora de dirigir los relojes de la Liga [...]. & \\
\hline
\end{tabular}

Fuente: elaboración propia

En la transcripción 3 el tema gira en torno a las entrevistas presenciales que se han realizado durante la emisión del espacio. La actualidad no es el parámetro temporal que determina la elección del contenido, ya que el autor del comentario se centra en varias anécdotas y accidentes que ha protagonizado el jugador Ever Banega desde su llegada a España. El rasgo más característico de esta estructura radiofónica es el estilo distendido y jocoso con el que se lleva a cabo: "Más nervioso que Messi en el control de altura del Dragon Khan" o "Lo de los coches con el argentino tiene menos futuro que un puesto de jamón en el centro de la Meca". Las risas y aplausos que se escuchan (el programa de esa jornada se celebró en un auditorio con presencia de público) reflejan a la perfección el enfoque humorístico de este tipo de género.

Con respecto a la música, el presentador del magacín da paso al responsable del comentario a través de las siguientes palabras: "Esta sintonía es la sintonía de Jordi Gosalvez". Con ello refuerza el carácter identificativo de dicho tema musical, al tiempo que justifica la elección del comentario como broche diario de la emisión: "Se me ocurrió que Jordi Gosalvez podía cerrar siempre Alprimer toque, y no lo hace mal". 
Transcripción 3. E1 comentario deportivo en Onda Cero ${ }^{7}$

\begin{tabular}{|lll|}
\hline VOZ & PARLAMENTO & OTROS \\
\hline & & SONIDOS \\
\hline Buenas noches, querido Héctor. Buenas noches, mi querida Valencia. No & Música \\
& esconderé que hoy realizo mi primer broche en directo y siento nervios, muchos & identifica- \\
Jordi & nervios. Más nervioso que Messi en el control de altura del Dragon Khan. Hoy es & tiva en \\
día eminentemente valencianista con protagonistas de primer nivel, entre los que & plano de \\
& destaco la presencia de Ever Banega. No se me preocupen, lo traje yo en bicicleta, fondo \\
& lo llevé yo al acabar en bicicleta incómodo pero seguro. Lo de los coches con el & \\
& argentino tiene menos futuro que un puesto de jamón en el centro de la Meca. & Aplausos \\
& Primero se atropella, luego se achicharra... Querido Ever, "Valenbisi". No se me & \\
& preocupen, también lo acosté, apagué el ordenador y apagué la webcam. Aunque & \\
& pensándolo bien, quién de aquí nunca practicó tal prueba de onanismo. & Risas \\
& Onanismo para aquellos no doctos es cuando uno [...]. & \\
\hline
\end{tabular}

Fuente: elaboración propia

En la transcripción 4 el comentario seleccionado se sostiene en la peculiar argumentación que realiza su autor con respecto a uno de los temas de actualidad más candentes durante la época de emisión del magacín. Tras el título "Bielsa ha renovado", se expone la razón por la que en tono distendido e irónico se cree que el tema sobre el futuro del entrenador del Athletic de Bilbao puede estar ya zanjado: "Se rumorea que se queda porque ha renovado el carnet del videoclub donde normalmente alquila sus películas". Tanto la conclusión final como los argumentos empleados carecen de validez futbolística alguna, ilustrando la trascendencia que adquiere el rumor y los contenidos extradeportivos en este tipo de programas.

El colaborador encargado de escribir y locutar el comentario subraya la ausencia de fuentes periodísticas fidedignas cuando al comienzo del texto utiliza la figura retórica de la redundancia con la palabra suposición: "Y suponer es gratis. Por lo tanto, suponemos que en el supuesto de que supuestamente...". Otro aspecto a destacar es el elevado ritmo de locución que caracteriza a este tipo de estructura en el espacio Abellán en punto, con una velocidad de dicción muy superior a la del resto de emisoras. 
Transcripción 4. E1 comentario deportivo en Abc Punto Radio ${ }^{8}$

\begin{tabular}{|c|c|c|}
\hline VOZ & PARLAMENTO & $\begin{array}{l}\text { OTROS } \\
\text { SONIDOS }\end{array}$ \\
\hline $\begin{array}{l}\text { Miguel } \\
\text { Ángel } \\
\text { Sevilla }\end{array}$ & $\begin{array}{l}\text { He titulado esta carta "Bielsa ha renovado". Bielsa se queda en el Athletic de } \\
\text { Bilbao. Esto no lo dice nadie, esto se supone. Y suponer es gratis. Por lo tanto, } \\
\text { suponemos que en el supuesto de que supuestamente se vaya o se quede, Bielsa } \\
\text { no se va. ¿Y por qué no se va? Porque se queda. ¿Y cuáles son las fuentes que nos } \\
\text { hacen suponer que supuestamente en el supuesto de que no se vaya, se quede? La } \\
\text { fuente es el videoclub que tiene junto al hotel donde se hospeda. José Antonio } \\
\text { Abellán es grande, pero a veces es muy grande. Y ayer hizo una pregunta que sólo } \\
\text { la gente grande la hace de vez en cuando. Pregunta que es la siguiente: ¿pero } \\
\text { todavía existe los videoclubs? Pues sí, don José Antonio Abellán. Todavía existen, } \\
\text { ¿y por qué existen? Porque todavía hay gente como Bielsa que alquila películas. A } \\
\text { Bielsa le hablas tú de que en Internet puede ver... y compra esas películas y te dice } \\
\text { que Internet es muy caro y que para tener Internet hay que tener un ordenador } \\
\text { que cuesta mucho dinero. Pues un videoclub es la premisa que aclara la cuestión y } \\
\text { el interrogante que a tanta gente nos quita el sueño: ¿je queda o se va Bielsa del } \\
\text { Athletic? Se rumorea que se queda porque ha renovado el carnet del videoclub } \\
\text { donde normalmente alquila sus películas [...]. }\end{array}$ & $\begin{array}{l} \\
\text { Música } \\
\text { orna- } \\
\text { mental en } \\
\text { plano de } \\
\text { fondo }\end{array}$ \\
\hline
\end{tabular}

Fuente: elaboración propia

\section{Conclusiones}

El comentario radiofónico se ha consolidado como una estructura de gran relevancia en el magacín deportivo. En el actual panorama de radio caracterizado por su naturaleza dialógica, la clave del éxito de este género monólogo reside en la peculiar visión de su autor a través de una estructura breve que difícilmente puede llegar a aburrir al oyente; tal como suele ocurrir en los comentarios de los programas de actualidad general. Durante la emisión de este magacín se advierte una enorme presencia de contenidos de opinión a través de entrevistas y tertulias, principalmente. El comentario consigue alcanzar su sello propio para distinguirse entre las numerosas impresiones y valoraciones que carentes de identidad formal se cuelan en el programa.

La palabra acompañada de la música se configura como el recurso fundamental sobre el que se sostiene su desarrollo. La utilización de figuras retóricas y la incorporación habitual de temas musicales altamente significativos (a diferencia de lo que ocurre en magacines de otras temáticas), hacen del comentario uno de los géneros radiofónicos de mayor expresividad. No obstante, hay que subrayar la ausencia de efectos sonoros y silencios, lo que a su vez refleja la escasa explotación expresiva que en líneas generales caracteriza a la radio española en la actualidad. 
El predominio del fútbol, las referencias a contenidos extradeportivos y el tono desenfadado sobre el que se desarrolla un importante número de comentarios, reflejan fielmente la adaptación del género a las pautas que guían la comunicación deportiva en las dos últimas décadas. La excepción se encuentra en la representación discursiva del oyente, ya que las apelaciones a su figura no alcanzan la continuidad que sí poseen en numerosos espacios radiofónicos.

Otros rasgos característicos que mantiene este tipo de comentario con los emitidos en programas no deportivos son las referencias a contenidos de actualidad sin que prime el valor de la inmediatez informativa; o la elección de los responsables de realizarlos y locutarlos en función del estilo y los objetivos que persiga cada emisora. En cualquier caso, el estudio del comentario debe tener más presencia dentro del ámbito científico y académico, con el fin de llevar a cabo un análisis profundo y exhaustivo de la evolución narrativa y discursiva que experimenta la radio en cada época.

\section{Bibliografía}

Álvarez, Ángels (2001): "Deporte y pasiones comunicativas: el caso del magacín radiofónico español”, en La educación física, el deporte y la salud en el siglo XXI (Coord., José Devís). Alicante: Marfil.

Álvarez, Miriam (1999): Tipos de escrito. II, Exposición y argumentación. Madrid: Arco Libros.

Adréu, Jaime (2000): "Las técnicas de Análisis de Contenido: Una revisión actualizada", Fundación Centro de Estudios Andaluces. Disponible en http://www.qualitativeresearch.net/index.php/fqs/rt/printerFriendly/1322/2798. [Consultado el 27-022014].

Bardin, Laurence (1986): Análisis de contenido. Madrid: AKAL.

Cebrián Herreros, Mariano (1992): Géneros informativos audiovisuales. Madrid: Ciencia 3.

Checa, Antonio (2005): "La radio deportiva al inicio del siglo XXI", en Comunicación y deporte. Nueva perspectivas de análisis (Coord., Joaquín Marín). Sevilla: Comunicación Social Ediciones y Publicaciones.

González Conde, $\mathrm{M}^{\mathrm{a}}$ Julia (2001): Comunicación radiofónica. Madrid: Universitas.

Guarinos, Virginia (2009): Manual de narrativa radiofónica. Madrid: Síntesis. 
Herrera, Susana (2009): "Las figuras retóricas en el comentario radiofónico", Linguagens Revista de Letras, Artes e Comunicaşão, Volumen 3, Número 3, p.p. 240-256.

---- (2004): "Caracterización del actual discurso de los programas de radio: factores de cambio y rasgos diferenciales", en El lenguaje radiofónico: la comunicación oral (Coords., Ignacio Blanco y Pilar Fernández). Madrid: Fragua.

Igartua, Juan J. (2006): Métodos cuantitativos de investigación en comunicación. Barcelona: Bosch Comunicación.

Krippendorff, Klaus (1997): Metodología del análisis de contenido. Teoría y práctica. Barcelona: Paidós.

Martínez-Costa, Pilar y Herrera, Susana (2008): "Rasgos característicos del comentario radiofónico", Textual and Visual Media, Número 1. Disponible en https://www.academia.edu/240115/Rasgos_caracteristicos_del_comentario_radiofo nico. [Consultado el 20-02-2014].

---- (2004): "Los géneros radiofónicos en la teoría de la redacción periodística en España: luces y sombras de los estudios realizados hasta la actualidad", Comunicación y Sociedad, Volumen 7, Número 1, pp. 115-144. Disponible en http://www.unav.es/fcom/comunicacionysociedad/es/articulo.php?art_id=76. [Consultado el 21-02-2014].

Martínez-Costa, Pilar y Díez Unzueta, J. Ramón. (2005): Lenguaje, géneros y programas de radio. Introducción a la narrativa radiofónica. Pamplona: Eunsa.

Merayo, Arturo (2002): “La construcción del relato informativo radiofónico", en Información radiofónica. Cómo contar las noticias en la radio de hoy (Coord., Pilar Martínez-Costa). Barcelona: Ariel Comunicación.

---- (1992): Para entender la radio: estructura del proceso informativo radiofónico. Salamanca: Universidad Pontificia de Salamanca.

---- y Pérez, Carmen (2001): La magia radiofónica de las palabras. Aproximación a la lingüistica en el mensaje de la radio. Salamanca: Cervantes.

Orozco, Guillermo (1995): La Investigación en comunicación desde la perspectiva cualitativa. La Plata (Argentina): Universidad Nacional de La Plata.

Ortiz, Miguel Á. y Marchamalo, Jesús (1997): Técnicas de comunicación en radio. La realización radiofónica. Barcelona: Paidós Ibérica.

Plantin, Christian (1998): La argumentación. Barcelona: Ariel. 
Paniagua, Pedro (2009): Cultura y guerra del fútbol: análisis del mensaje informativo. Barcelona: Editorial UOC.

Piñuel, José L. y Gaitán, Juan A. (1995): Metodología general. Conocimiento científico e investigación en la Comunicación Social. Madrid: Síntesis.

Ramallal, Manuel (2003): Sociedad y deporte: análisis del deporte en la sociedad y su reflejo en los medios de comunicación. [Tesis doctoral]. Universidad de La Coruña: UCD, Sociología y Ciencia Política de la Administración. Disponible en http://www.tesisenred.net/TDR-0425106145348. [Consultado el 13-02-2014].

Rodero, Emma (2005): Producción radiofónica. Madrid: Cátedra.

Santamaría, Luisa (1990): El comentario periodístico. Los géneros persuasivos. Madrid: Paraninfo.

Spang, Kurt (2005): Persuasión. Fundamentos de retórica. Pamplona: Eunsa.

Wolf, Mauro (1984): “Géneros y televisión”, Anàlisi: Quaderns de comuniaciò y cultura, Número 9, pp. 189-198.

http://www.ivoox.com/ [Página web del audiokiosko Ivoox].

http://www.cadenaser.com/ [Página web de la Cadena SER].

http://www.cope.es/ [Página web de la cadena COPE].

http://www.ondacero.es/ [Página web de la cadena Onda Cero].

\section{Notas}

1 La mayoría de emisoras coinciden en presentar su nueva programación así como los cambios más significativos con respecto a la temporada anterior a comienzos de septiembre, manteniéndolos hasta los meses de verano del siguiente año natural.

2 Para más información exhaustiva sobre esta cuestión, consultar el artículo de Susana Herrera titulado (2009) Las figuras retóricas en el comentario radiofónico.

3 Según Álvarez, este tipo de estructura en el magacín deportivo trae consigo una cadencia calmosa y la configuración de un ritmo estructural sosegado (2000: 207).

4 En relación al tiempo presente, se distingue la configuración de informaciones previas, acontecimientos en sí mismos, o informaciones posteriores, en función de si se alude al 
evento en cuestión un día antes, el mismo día, o un día después de su celebración, respectivamente (Ramallal, 2003: 220.). El resto de coyunturas informativas se pueden corresponder con el tiempo pasado (si la distancia temporal es igual o mayor a dos días en relación al momento de su celebración), o futuro (si la distancia temporal es igual o superior a dos días con respecto al momento en que tiene lugar) (Ídem). La presencia de contenidos asociados a cualquiera de estas dos últimas dimensiones temporales se relaciona estrechamente con la trascendencia que el programa otorga a dichos contenidos. "No finalizado": tiempo de unidades de análisis con acontecimientos deportivos que se alargan más de una jornada. "Múltiple": tiempo de unidades de análisis que tratan varias contenidos deportivos con desarrollo temporal diferente. "Indeterminado": tiempo de unidades de análisis no vinculadas a un acontecimiento o contenido deportivos, o de aquellas otras en las que los sujetos del enunciado no aportan datos suficientes para conocer el momento de su celebración. Estas dos últimas dimensiones se pueden dar igualmente dentro del tiempo presente, pasado y futuro.

${ }^{5}$ Programa El larguero emitido el 04-09-2012.

6 Programa El partido de las 12 emitido el 21-03-2012.

7 Programa Al primer toque emitido el 15-11-2012.

8 Programa Abellán en punto emitido el 30-05-2012. 


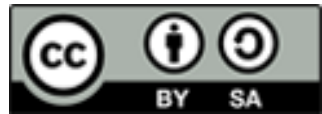

Licencia Creative Commons

Miguel Hernández Communication Journal

mhcj.es

\section{Forma de citar este artículo en las bibliografías}

Hilario José Romero Bejarano (2014): “Las dimensiones narrativas del comentario radiofónico en el magacín deportivo”, en Miguel Hernández Communication Journal, n5, páginas 113 a 140. Universidad Miguel Hernández, UMH (Elche-Alicante). Recuperado el _ de de

20__de: http: $/ /$ mhcj.es. $/$ index.php?journal $=$ mhcj\&page $=$ article\&op $=$ view\&path $\square=59$ 